\title{
"NÓS CONCORDAMOS
}

\section{EM PESSOA E NÚMERO, PORÉM,}

NÓS DISCORDA BASTANTE.

" UM ESTUDO DOS PRONOMES

DE PRIMEIRA PESSOA

\section{PLURAL EM PB COM BASE EM UM}

\author{
CORPUS DE \\ FALA POPULAR
}

"NÓS CONCORDAMOS EM PESSOA E NÚMERO, PORÉM, NÓS DISCORDA BASTANTE." UN ESTUDIO DE LOS PRONOMBRES DE LA PRIMERA PERSONA DEL PLURAL EN PB BASADO EN UN CORPUS ORAL

"NÓS CONCORDAMOS EM PESSOA E NÚMERO, PORÉM, NÓS DISCORDA BASTANTE." A STUDY OF FIRST PERSON PLURAL PRONOUNS IN BP BASED ON A POPULAR SPEECH CORPUS 
RESUMO: No Português Brasileiro (PB), as tradicionalmente chamadas "formas nominativas" dos pronomes são também representantes oblíquos, sem nenhuma marginalidade em sua aceitação, não havendo uma correspondência unívoca entre uma forma pronominal e uma única função casual/gramatical, como esperado para o Português Europeu (PE). Argumentamos que os pronomes de primeira pessoa plural "nós" e "a gente" integram o sistema vernacular de pronomes do $\mathrm{PB}$ e não concorrem entre si. Embasados nos pressupostos da teoria da Gramática Gerativa, partimos da hipótese de que o reflexo da mudança gramatical do PB, relacionada à oposição de um sistema composto por 6 (seis) pessoas gramaticais em direção a uma oposição dual (primeira/terceira pessoa singular), tem como consequência uma mudança nos traços gramaticais dos pronomes que deixam de ser marcados como nominativo no léxico, sendo o paradigma de pronomes do vernáculo brasileiro caracterizado por um paradigma flexional e um sistema de concordância distinto do PE.

PALAVRAS-CHAVE: Pronomes. Português Brasileiro. Gerativismo. Variação linguística.

RESUMEN: En el portugués de Brasil (PB), las tradicionalmente denominadas "formas nominativas" de pronombres son también representantes oblicuos sin ningún tipo de marginalidad en su aceptación, sin una correspondencia unívoca entre la forma pronominal y una función única casual, como en el portugués Europeo (PE). En este trabajo se argumenta que los pronombres "nós" y "a gente" (nosotros) son parte del sistema de pronombres del PB y no compiten entre sí. Basados en los principios de la Teoría Generativa, partimos del supuesto de que el reflejo del cambio gramatical, relacionado con la oposición de un sistema compuesto por seis personas gramaticales hacia una oposición dual (primera/tercera persona), tiene como consecuencia un cambio en las características gramaticales de los pronombres que dejan de ser marcados como nominativo en el léxico, siendo el paradigma de pronombre del PB caracterizado por una flexión y un sistema de concordancia distintos del PE.

PALABRAS CLAVE: Pronombres. Portugués brasileño. Gerativismo. La variación lingüística.

ABSTRACT: The traditionally called "nominative forms" of pronouns are also oblique representatives without any marginality in its acceptance in Brazilian Portuguese (BP). There is no univocal correspondence between a pronominal form and a unique casual function, as expected in European Portuguese (EP). We also argue, in this work, the plural first-person pronouns integrate the vernacular system of BP pronouns and do not compete with each other. Based on the assumptions of the Generative Theory, we argue that the grammatical change, related to the opposition of a system composed by six grammatical persons toward an opposition of first and third person singular, has as consequence a change in the grammatical features of the pronouns that are no longer marked as nominative in the lexicon; so, the Brazilian vernacular pronoun paradigm is characterized by a flexional paradigm and a concordance system distinct from EP.

KEYWORDS: Pronouns. Brazilian Portuguese. Generative grammar. Linguist variation.

\section{INTRODUÇÃOO}

A inserção de "a gente" no paradigma pronominal do Português Brasileiro (PB) tem atraído a atenção de vários autores (OMENA, 1986; DUARTE, 1993; LOPES, 1996, 1998, 1999, 2002, 2004) que se propuseram a investigar não só a sua gramaticalização, mas também a possibilidade de essa nova forma pronominal vir a substituir a forma mais antiga "nós", na primeira pessoa do plural; variação caracterizada pela literatura atual como "mudança em curso".

As pesquisas na área da Sociolinguística procuram mostrar que a mudança linguística decorrente da gramaticalização de "a gente", pronominalizando o Sintagma Nominal "a gente", afetou o sistema pronominal do PB em alguns de seus traços mais abstratos, desencadeando uma suposta disputa entre as formas "nós" e "a gente" para ocupar a posição de primeira pessoa do plural. Ao revisitarmos os dados de pesquisa de vários autores, e observarmos a fala popular de Vitória da Conquista-BA, tanto o uso de "nós" quanto o uso de "a gente" nos pareceram bastante estáveis na língua do Brasil. Tal fato nos despertou a dúvida sobre a natureza da variação encontrada no uso dessas formas pronominais. Logo, decidimos investigar o já conhecido, sob uma nova perspectiva, apoiada no quadro teórico da Gramática Gerativa e nas considerações sobre a variação e a mudança linguística de Kroch (1989a, 1989b, 1994, 2001). A primeira questão que colocamos veio da dúvida despertada, interrogando, assim, a natureza da variação no uso dos pronomes "nós" e "a gente". Essa primeira questão relaciona-se a uma segunda que indaga se "nós" e "a gente" são de fato formas pronominais em competição, com a previsão de que a forma inovadora "a gente" irá substituir a forma "nós”, em analogia

Namiuti \& Vieira Nósconcordamos em pessoa e número, porém, nós discortabastante. "Um estudo dos pronomes... 
ao que aconteceu com a forma pronominal sujeito de segunda pessoa do plural “vós”, hoje extinta do sistema pronominal vernacular do $P B{ }^{1}$.

Defendemos a hipótese ${ }^{2}$ de que ambos os pronomes de primeira pessoa do plural ("nós" e "a gente") integram o sistema vernacular de pronomes do $\mathrm{PB}$, o que implica dizer que tais formas pronominais convivem numa mesma gramática e não competem no sistema.

A proposta, aqui defendida, não se aplica aos casos claros de competição gerada pelo confronto entre um vernáculo brasileiro e um vernáculo europeu, por vezes refletido em um português culto do Brasil. Trata-se de conclusões provenientes da observação e da análise de dados de fala popular, que convergem para a defesa da existência de um pronome "nós" no paradigma de pronomes do vernáculo brasileiro, caracterizado por um paradigma flexional e um sistema de concordância distinto do Português Europeu (PE).

Diferentemente do paradigma flexional do verbo, o paradigma pronominal do PB parece manter os traços que derivam as seis pessoas gramaticais. É a competição entre um sistema inovador que possui pronomes "nós" e "a gente" não marcados para caso, e que gera sentenças como (a) "Nós/a gente não concorda ...."; e (b) "Ele entregou a carta pra nós/a gente"; versus um sistema antigo de pronomes, característico do PE com "nós" e "a gente", marcados como nominativos na primeira pessoa do plural, e que pode gerar sentenças como (c) "Nós/a gente concordamos ..."; (d) "Ele nos entregou a carta"; que compõe o cenário da língua no Brasil. Acreditamos que a alteração no sistema deve estar associada ao enfraquecimento da concordância (Agr), retomando a proposta seminal de Galves (1993).

\section{O ESTADO DA ARTE E A IDENTIFICAÇÃO DO PROBLEMA}

De acordo com Lopes (2004), aparentemente, a forma nova "a gente" tem ganhado espaço nos últimos 40 anos, tanto entre os falantes cultos, quanto entre os não cultos, principalmente os jovens, com faixa etária de até 25 anos (LOPES, 2004, p.186). Omena (2003) argumenta que, ao longo dos anos, os falantes adquirem a forma mais antiga ("nós") na escrita padrão, uma vez que ela ainda é dotada de maior prestígio na sociedade.

Lopes (1998) analisa a variação de "nós" e "a gente" em posição de sujeito, tendo como corpus dados de falantes cultos das três principais regiões geográficas do Brasil: Sudoeste (Rio de Janeiro), Sul (Porto Alegre) e Nordeste (Salvador); dados oriundos do Projeto da Norma Urbana Oral Culta (NURC). A autora compara os seus resultados com o trabalho de Omena (1986), que tem por base a fala popular.

Em seus dados, Lopes (1998) identifica quatro possibilidades para se referir à $1^{\text {a }}$ pessoa do discurso no plural, utilizadas pelo falante culto: "nós", explícito ou não, seguido da desinência -mos, e "a gente", explícito ou não, seguido de morfema zero ${ }^{3}$ (Ø desinência verbal para a $3^{\text {a }}$ pessoa singular).

Duarte (1993) atesta que os paradigmas flexionais do português no Brasil estão sofrendo modificações oriundas do uso de variantes inovadoras como "você/vocês" e "a gente". Segundo a autora, tais modificações destituem as formas tradicionais "tu/vós" e "nós". Apesar de "a gente" indicar o discurso realizado por algumas pessoas com inclusão do falante, logo, referir-se à primeira pessoa do plural, assim como " você", desencadeia concordância com a terceira pessoa gramatical, ou seja recebe marcação Ø para a flexão número pessoal do verbo, o que, ainda segundo Duarte (1993), reduz as desinências verbais que compõem as conjugações do PB.

\footnotetext{
${ }^{1}$ Não há estudos que apontam o registro de aquisição do pronome sujeito "vós” na fala de crianças em fase de aquisição da linguagem.

${ }^{2}$ As reflexões aqui apresentadas são oriundas de pesquisa realizada no âmbito dos projetos temáticos - Fapesp 2012/06078-9, Fapesb APP0007/2016, Fapesb APP0014/2016 e CNPq 471753/2014-9 - e contemplam resultados da dissertação de mestrado Nós e a gente: um estudo sobre a sintaxe do Português Brasileiro, defendida por Adilma S. O. Vieira em 2014, orientada por Cristiane Namiuti e financiada pela CAPES. 


\begin{tabular}{|c|c|c|c|c|}
\hline Pessoa & Número & Paradigma 1 & Paradigma 2 & Paradigma 3 \\
\hline $1^{\mathrm{a}}$ & Singular & Cant-o & Cant-o & Cant-o \\
\hline $2^{\mathrm{a}}$ direta & Singular & Canta-s & ----- & ---- \\
\hline $2^{\mathrm{a}}$ indireta & Singular & Canta- $\varnothing$ & Canta- $\varnothing$ & Canta- Ø \\
\hline $3^{\mathrm{a}}$ & Singular & Canta-Ø & Canta-Ø & Canta-Ø \\
\hline $1^{\mathrm{a}}$ & Plural & Canta-mos & Canta-mos & Canta-Ø \\
\hline $2^{\mathrm{a}}$ direta & Plural & Canta-is & --- & --- \\
\hline $2^{\mathrm{a}}$ indireta & Plural & Canta-m & Canta-m & Canta-m \\
\hline $3^{\mathrm{a}}$ & Plural & Canta-m & Canta-m & Canta-m \\
\hline
\end{tabular}

Tabela 1: Evolução dos paradigmas flexionais do português segundo Duarte (1993)

Fonte: Duarte (1993, p. 109).

O paradigma 1 é composto por seis desinências verbais que marcam as flexões -o, -s, - Ø, -mos, -is e - $m$, características da língua portuguesa, cuja realidade linguística é atestada em Portugal, mas não no Brasil. No paradigma 2, há algumas modificações relacionadas à segunda pessoa, em que se perdem as desinências -s e -is, características das pessoas "tu" e "vós", dando lugar às expressões "você" e "vocês", que apesar de se referirem à segunda pessoa, possuem marcações Ø. Há, portanto, uma redução de 6 para 4 formas desinenciais. No paradigma 3, são encontradas, além das mudanças de segunda pessoa, uma redução da desinência mos, característica da forma tradicional, e consequente acréscimo da desinência Ø, marcadora do "a gente”, o que para Duarte (1993) indica a substituição de "nós" por "a gente". Assim, há no paradigma flexional do verbo um decréscimo de seis formas iniciais para apenas três formas verbais atuais ou até mesmo duas, se não se considerar a sexta pessoa (P6), como já acontece na fala (PAIVA; DUARTE, 2006), relacionado a uma mudança no paradigma de pronomes pessoais.

Lemos Monteiro (1994, p. 146-147, grifos do autor) também atenta para a mudança dos paradigmas pronominais do Português, quando afirma que:

O sistema dos pronomes pessoais, conforme vimos insistindo, está sofrendo uma profunda reestruturação correlacionada a uma simplificação do paradigma de conjugação verbal. Certas mudanças já se encontram plenamente consumadas, como a substituição do pronome vós por vocês, enquanto outras ainda lutam por impor-se, tal qual o caso do emprego de a gente em vez de nós.

De acordo com Lemos Monteiro (1994), a nova forma "a gente" tem seguido os passos traçados por “você".

Todavia, a associação entre a redução do paradigma flexional do PB e a modificação do paradigma pronominal não nos parece assim tão óbvia. Buscamos aqui traçar um raciocínio diferente, desatrelando a propriedade flexão da propriedade concordância.

Ao mesmo tempo em que a desinência -mos se torna menos produtiva na língua, cresce o uso dos sujeitos preenchidos e se criam expressões como "Nós vai/ Nós canta”. Tais alterações parecem caracterizar claramente uma mudança gramatical no paradigma flexional do verbo em PB associada a uma mudança no sistema de concordância da língua. No entanto, ousamos dizer que as alterações no sistema de concordância (que para nós é mais importante e precede as alterações no paradigma flexional) não são necessariamente engatilhadas pelas formas novas no paradigma de pronomes. Ousamos ainda sugerir que a variação das formas "nós" e "a gente" em PB não se configura em competição, ou seja, é precipitada a conclusão que prevê o desaparecimento da forma pronominal "nós", pelo menos em relação aos traços lexicais mais superficiais desse pronome. As impressões que os dados aqui 
examinados imprimem são para a permanência do "nós" como pronome no PB vernacular, com alteração em alguns de seus traços formais, sendo a mudança mais significativa e geral localizada no sistema de concordância, mais especificamente a concordância de número, noção esta que, no paradigma flexional do verbo, está amalgamada à expressão dos traços de pessoa do discurso (também expressa pela flexão verbal em Português).

\section{NÓS E A GENTE NA FALA POPULAR DE VITÓRIA DA CONQUISTA}

Os dados elencados na formação do corpus de Fala Popular de Vitória da Conquista-BA foram coletados (FPVC) no ano de 2007 sob a supervisão e orientação da Profa. Dra. Cândida Mara Brito Leite (UESB), no âmbito do Grupo de Pesquisa em Estudos Linguísticos (GPEL/UESB), visando a formação de um banco de dados que contribuísse para as futuras investigações de pesquisadores do grupo, não estando, até o presente momento, disponível online. Para este trabalho foram selecionadas entrevistas de doze informantes naturais desta cidade, com grau de escolaridade de até, no máximo, 4 anos, caracterizando a fala popular, cuja escolaridade se limita a analfabetos ou semianalfabetos. Os informantes se dividiram em três faixas etárias, havendo dois informantes de cada sexo em cada faixa etária. A fim de manter o sigilo dos informantes, utilizamos apenas as iniciais de seus nomes.

As gravações foram realizadas através de conversas informais, em entrevista narrativa, com livre interação entre os interlocutores, em formato mp3, com duração média de 60min. Os dados de fala foram transcritos pelos próprios documentadores, sendo revisados, posteriormente, para fins deste trabalho, em especial os casos que envolvem o nosso objeto de estudo: o fenômeno nós/a gente. Vale salientar que não há critérios de transcrição estabelecidos que envolvam prosódia ou fonética; as transcrições foram realizadas utilizando-se o critério de transcrição ortográfica, sendo necessário retornar às gravações, se preciso.

Na FPVC, foram computadas 818 ocorrências de "nós" e "a gente", sendo 654 casos em posição de sujeito e 164 em outras posições sintáticas. Para fins de análise de concordância, na posição sujeito, deixamos à margem do nosso estudo alguns marcadores discursivos, pronomes com verbos elididos e ambiguidades interpretativas, o que totalizou 595 casos de "nós" e "a gente" nessa função $(78,4 \%)$ e 164 dessas formas em outras funções sintáticas $(21,6 \%)$.

A posição sujeito compreende quatrocentos casos de "a gente" (67,2\%), 177 realizações de "nós" (29,8\%) e dezoito ocorrências de sujeito nulo em primeira menção - mos (3\%). Já em outras funções sintáticas, obtivemos 109 (66,5\%) e 55 (33,5\%) casos de "a gente” e "nós", respectivamente.

\section{1 "NÓS" VS "A GENTE" NA FUNÇÃO DE SUJEITO DA SENTENÇA}

Foram identificadas sete possibilidades ${ }^{4}$ para se referir à $1^{\text {a }}$ pessoa do discurso no plural, em um quadro um pouco diferente de Lopes (1998) e Vianna e Lopes (2003), são elas: (1) “nós” realizado lexicalmente, seguido da desinência -mos; (2) "nós” realizado lexicalmente, seguido do morfema Ø; (3) “a gente” seguido da desinência verbal Ø; (4) sujeito nulo de primeira menção representado pela desinência -mos; (5) "nós" implícito seguido da desinência -mos (P4); (6) "nós" implícito seguido do morfema Ø (P3); (7) "a gente" implícito seguido do morfema Ø (P3). Não foram encontradas, nos dados de FPVC, as concordâncias entre "a gente” + P4 e "a gente" + P6.

(01) "O que gera a violência é falta de emprego, falta de policiamento bom na cidade, falta de várias coisas que nós precisamos em Vitória da Conquista." (ETM, 1f)

\footnotetext{
"Então nós chegava assim, 'Já comeu, os menino?” (ETF, 2m)
}

\footnotetext{
${ }^{4}$ Uma oitava possibilidade foi supostamente atestada neste corpus: "nós” explícito seguido de P6 (3ª pessoa do plural): (i) "dois são nós, são os próprios nós, né? (DRS, 3m). Entretanto, os dois dados reproduzidos em (i) são os únicos atestados neste padrão de concordância, e, por se tratar de uma estrutura predicativa, não está livre de ambiguidade em PB uma vez que a forma "nós" aparece em estrutura de complementação e, portanto, pode ser analisado como predicativo do sujeito de $3^{\text {a }}$ pessoa plural - referente: "dois".
} 
"No posto às vezes a gente ligava pra ambulância." (RRS, 1m)

(04) “(P4)Moremos assim na roça que meu pai era era era faz::... vaqueiro.” (MdS, 3f)

(05) "É o mês de março, nós ficou muito alegre, (nós) ficamos feliz [...]" (ETM, 1f)

(06) “Ai o que nós fazia, nós ia num caçar faxina, (nés) pegava uns preguim ...” (MCF, 2m)

(07) “Todos os dia (...) vou na casa dum camarada meu, que ele sempre arruma um... um trabalho pra fazer, a gente faz, (a gente) constrói um algodão doce pra vender durante a semana, no sábado no domingo... as vezes." (RRS, $\operatorname{lm})^{5}$

Foram considerados dados de sujeito implícito em orações dependentes, coordenadas ou subordinadas, cujo antecedente era realizado lexicalmente, para evitar ambiguidade interpretativa. Os casos em que o pronome lexical ("nós" ou "a gente") não pode ser recuperado no discurso foram separados dos casos de sujeito implícito por considerarmos que sua representação estrutural pode ser diferente, tais casos foram classificados como casos de sujeito nulo de primeira menção (flexionados em primeira pessoa plural - P4 - ou seja, apresentam, categoricamente, a desinência "mos" associada à categoria vazia que representa o conteúdo lexical do sujeito).

A fim de comprovarmos a nossa hipótese, consideramos os seguintes fatores condicionantes ao uso da primeira pessoa do plural na posição sujeito: (1) explicitude do sujeito ${ }^{6}$, (2) tipo de verbo ${ }^{7}$, (3) tipo de predicado $^{8}$, (4) tempo verbal ${ }^{9},(5)$ modo verbal $^{10}$, (6) flexão verbal $^{11},(7)$ saliência fônica ${ }^{12},(8)$ controle de referente $^{13},(9)$ sexo e (10) faixa etária.

Apesar de uma preferência pelo pronome "a gente", as ocorrências de "nós" são bastante significativas no corpus de FPVC, nesta função, e precisam ser melhor investigadas.

\subsubsection{EXPLICITUDE DO SUJEITO E FLEXÃO VERBAL}

No que se refere ao fator explicitude do sujeito, não nos parece possível afirmar que há um favorecimento para o uso de uma forma específica em virtude da elipse do sujeito. De maneira geral, verificamos na FPVC a preferência dos falantes pelo uso do sujeito preenchido, tanto com a forma "a gente" quanto com a forma "nós".

\footnotetext{
${ }^{5}$ Os dados foram destacados em negrito; o sujeito implícito e o sujeito nulo de primeira menção aparecem indicados entre parênteses e tachados, o referente do sujeito implícito está indicado nos exemplos por sublinhado.

${ }^{6}$ i) Sujeito explícito "nós"; ii) Sujeito explícito “a gente”; iii) Sujeito implícito "nós” (verificado em orações anteriores); iv) Sujeito implícito "a gente" (verificado em orações anteriores); v) Sujeito nulo em P4 (primeira menção do sujeito).

${ }^{7}$ i) Acusativo de 2 ou 3 lugares; ii) Transitivo de 2 lugares com complemento oblíquo; iii) Inacusativo; iv) Inergativo.

${ }^{8}$ i) Simples; ii) Complexos modo-temporais; iii) Voz passiva; iv) Condicional; v) Outros (Expressão “Tem que")

${ }^{9}$ i) Presente; ii) Pretérito perfeito; iii) Pretérito imperfeito; iv) Futuros; v) Formas nominais com ausência de auxiliares; vi) Condicional.

${ }^{10}$ i) Indicativo; ii) Subjuntivo; iii) Infinitivo; iv) Gerúndio.

${ }^{11}$ i) primeira pessoa do plural (P4); ii) terceira pessoa do singular (P3); iii) terceira pessoa do plural (P6).

${ }^{12}$ i) Esdrúxula; ii) Máxima; iii) Média; iv) Mínima.

${ }^{13}$ i) Referente genérico e indefinido: uma categoria generalizada e indeterminada de indivíduos; ii) Referente genérico e definido: categoria generalizada, mas determinada de indivíduos; iii) Referente específico e definido [misto]: uma categoria específica e determinada de indivíduos, que engloba homens e mulheres; iv) Referente específico e definido [homens exclusivo]: uma categoria específica e determinada de indivíduos, que engloba apenas homens; v) Referente específico e definido [mulheres exclusivo]: uma categoria específica e determinada de indivíduos, que engloba apenas mulheres. Forma precedida de sujeito nulo -mos.
} 
Bortoni-Ricardo (1985) e Rodrigues (1987) constataram que a ausência ou elipse de sujeito favorece a marcação do morfema -mos. Omena (1986), Lopes (1993, 1998), dentre outros autores, ressaltaram que há influência do preenchimento ou apagamento do sujeito no fenômeno de alternância pronominal nós/a gente. Vianna (2011), em estudos com amostras de fala do português europeu (PE), verificou a predominância do emprego de sujeito nulo em P4. Com a forma pronominal "a gente", o emprego de sujeito não preenchido lexicalmente praticamente não se deu, prevalecendo os casos de sujeito explícito.

Em contraponto a Bortoni-Ricardo (1985), Rodrigues (1987), e Vianna (2011), o fato de não haver sujeito preenchido não favorece, aqui, o uso de -mos, tampouco se refere ao pronome "nós", uma vez que há uma grande quantidade de sujeito não preenchido cujo referente é "a gente". Reparemos que a distribuição entre nós e "a gente" não realizados lexicalmente não apresenta grande diferença, pois, se considerarmos que as ocorrências de primeira menção também representam um "nós" não realizado lexicalmente, uma vez que não foram atestados casos de "a gente" lexical co-ocorrendo com o morfema -mos, temos quarenta casos do pronome "nós" elidido, ou seja, $42 \%$ das ocorrências de sujeito implícito (tabela 2).

Esses resultados sugerem que o fator Explicitude do Sujeito, que controla os contextos de sujeito explícito e de sujeito não explícito, possui pouca influência no processo de alternância pronominal nas amostras consideradas - o pronome "a gente" será mais produtivo em ambos os casos.

(08) “No posto às vezes a gente ligava pra ambulância." (RRS, $1 \mathrm{~m}$ )

(09) “Então nós chegava assim, 'Já comeu, os menino?” (ETF, 2m)

(10) "Todos os dia (...) vou na casa dum camarada meu, que ele sempre arruma um... um trabalho pra fazer, $\underline{\text { a gente }}$ faz, (a gente) constrói um algodão doce pra vender durante a semana, no sábado no domingo... às vezes." (RRS, 1m)

(11) “Ai o que nós fazia, nós ia num caçar faxina, (nóis) pegava uns preguim, (nóis) pregava ali nos carrim..." (MCF, $2 \mathrm{~m})$

(12) “É o mês de março, nós ficou muito alegre, (nós)ficamos feliz [...]" (ETM, 1f)

(13) “(P4) Moremos assim na roça que meu pai era era era faz:.... vaqueiro.” (MdS, 3f)

A flexão verbal, por sua vez, se apresenta como um fator altamente relevante para a nossa pesquisa, pois a observação da não correspondência entre a flexão verbal e o pronome sujeito, em $\mathrm{PB}$, e dos traços mais salientes para a concordância variável nos possibilitou lançar um novo olhar para a natureza da variação nos usos de "nós" e "a gente" e sua relação com a mudança gramatical que aconteceu no Brasil, gerando o PB.

Ao observar os resultados gerais para a concordância verbal de $1^{\text {a }}$ pessoa do plural, Rubio (2012) verificou que no PB há uma frequência considerável de uso de formas verbais de $3^{\text {a }}$ pessoa do singular junto ao pronome "nós" (14,5\%), enquanto no PE é categórico o uso de morfemas de $1^{\circ}$ pessoa do plural nesse contexto. Por outro lado, verificou-se que o uso de "a gente" + P3 representa 94\% dos casos no PB e de 75,5\% no PE, sendo o emprego de a gente + P4 quase 20\% maior nas amostras de Portugal.

Lopes (1999), em estudos com falantes cultos do PB, afirma, porém, que a concordância de "a gente" com verbo na $3^{\text {a }}$ pessoa do singular é categórica ("A gente vai”). Já a concordância de nós com verbo na $1^{\text {a }}$ pessoa do plural ou $4^{\text {a }}$ pessoa (P4) foi a única estratégia localizada (Nós vamos.).

Notamos, em nossos estudos, o uso do morfema de terceira pessoa do singular $\varnothing$ estabelecendo concordância com o pronome "a gente", como já era esperado, mas também com o pronome "nós", diferindo, de maneira geral, dos resultados exibidos pela literatura até o momento. 
Total

\begin{tabular}{|c|c|c|c|c|c|}
\hline & & & & \multicolumn{2}{|c|}{ Total } \\
\hline \multirow{5}{*}{ A gente } & \multirow{3}{*}{ Explícito } & P3 & $\begin{array}{c}340 \\
85,0 \%\end{array}$ & \multirow{3}{*}{$\begin{array}{c}344 \\
86,0 \%\end{array}$} & \multirow{5}{*}{$\begin{array}{c}400 \\
67,2 \%\end{array}$} \\
\hline & & P4 & 0 & & \\
\hline & & Gerúndio & $\begin{array}{c}4 \\
1,0 \%\end{array}$ & & \\
\hline & \multirow[t]{2}{*}{ Implícito } & P3 & $\begin{array}{c}56 \\
14,0 \%\end{array}$ & \multirow{2}{*}{$\begin{array}{c}56 \\
14,0 \%\end{array}$} & \\
\hline & & P4 & 0 & & \\
\hline \multirow{4}{*}{ Nós } & \multirow[b]{2}{*}{ Explícito } & P3 & $\begin{array}{c}126 \\
70,5 \%\end{array}$ & \multirow{2}{*}{$\begin{array}{c}157 \\
87,8 \%\end{array}$} & \multirow{4}{*}{$\begin{array}{c}177 \\
39,8 \%\end{array}$} \\
\hline & & P4 & $\begin{array}{c}29 \\
16,2 \%\end{array}$ & & \\
\hline & \multirow{2}{*}{ Implícito } & P3 & $\begin{array}{c}16 \\
8,9 \%\end{array}$ & \multirow{2}{*}{$\begin{array}{c}22 \\
12,2 \%\end{array}$} & \\
\hline & & P4 & $\begin{array}{c}6 \\
3,3 \%\end{array}$ & & \\
\hline & - primeir & & & & $\begin{array}{c}18 \\
3,0 \%\end{array}$ \\
\hline & Total & & & $\begin{array}{c}595 \\
100 \%\end{array}$ & \\
\hline
\end{tabular}

Tabela 2: Explicitude do sujeito e flexão verbal

Fonte: Elaboração própria com base nos resultados de Vieira (2014)

A tabela 2 revela que o uso de "a gente" concordando com P3 é categórico, apresentando-se em 100\% dos casos, corroborando os dados de Lopes (1998), com falantes cultos, mas diferenciando-se do que foi visto por Vianna e Lopes (2003), em estudo com os falantes de menor grau de escolaridade, uma vez que as autoras verificaram a presença de concordância entre "a gente" + P4 e "a gente" + P6.

Por outro lado, o uso de "nós" concordando com P3 (80,2\%) se apresenta excessivamente maior do que a concordância com P4 (19,8\%), aguçando uma diferença de percentual relevante entre os dados aqui expostos e os resultados apresentados em Lopes (1998) e Vianna e Lopes (2003).

Em contextos cuja relação entre verbo e sujeito é estabelecida somente por meio da concordância verbal, Rodrigues (1987) afirma que há no sujeito implícito "nós" um favorecimento para o uso de formas verbais marcadas, diferente do resultado encontrado em nossa pesquisa. Na FPVC, tanto os sujeitos explícitos, quanto os sujeitos implícitos, expressos em orações anteriores, para "nós" e para "a gente", a concordância com P3 é favorecida; lembremos de que os sujeitos nulos, sem referencial antecedente, remetem ao uso de P4. Essa informação valida ainda mais a nossa hipótese de que há uma redução (de número) no paradigma flexional, em que os falantes apresentam uma tendência ao uso do morfema $\emptyset$.

Vianna e Lopes (2003) ressaltam que há uma menor produtividade na concordância de "nós" + P3, justificando o seu uso a construções escolhidas pelo falante: a) posposição do sujeito, b) pausa entre o pronome sujeito e o verbo, c) presença de quantificadores universais. Foram encontrados nos dados de fala conquistense apenas: dois casos de pausa entre o pronome sujeito e verbo e cinco casos com a presença de quantificadores universais: 
i) Pausa entre o pronome sujeito e o verbo

(14) “[...] as vezes nós, nós nessa idade, tá nessa idade de sessenta e tantos anos.” (DRS, 3m)

(15) "Eu espero minha filha ...as ... nós aqui dá o ... a saúde [...]" (MdS 3f)

ii) Presença de quantificadores universal

(16) “Todos nós passar no concurso" (ETF, 2m)

(17) "nós ficava todo mundo ali, os filhos todo ali, rodiando, olhando ele até na hora que ele que ele que ele morreu" (DRS, 3m)

(18) "Nós todos tem uma cruz pra carregar, que trazemos essa cruz de nascença." (ETM 1f)

(19) "Nós tava tudo preocupado... já com ele..." (IJG 2f)

(20) “É... porque nós tudo né? foi criado junto." (IJG 2f)

Diante da quantidade significativa de ocorrências de "nós" + Ø nos dados da FPVC, não se pode atribuir a concordância de "nós" com o morfema Ø a uma simples "intercambialidade existente entre as formas nós e a gente". A nosso ver, o que ocorre no vernáculo do PB é uma mudança no valor do traço de concordância que atinge a gramática como um todo, refletindo na marcação do traço plural apenas na parte funcional mais alta nos sintagmas verbais (e nominais).

\subsubsection{OUTROS FATORES LINGUÍSTICOS LIGADOS AO VERBO}

Os fatores (i) tipo de verbo, (ii) tipo de predicado e (iii) modo verbal foram utilizados experimentalmente por "nós", numa tentativa de saber se essas variáveis influenciam no processo de alternância pronominal nós/a gente. Ao analisarmos a influência de cada grupo de fatores, verificamos que a frequência do uso de "a gente" ( $>60 \% \mathrm{e}<70 \%)^{14}$ é sempre superior à frequência de uso de "nós" ( $>30 \%$ e $<40 \%)$. No entanto, o uso da forma "nós" não parece marginal sendo a proporção sempre a mesma para ambas as formas.

O fator tempo verbal é considerado significativo nos estudos de Omena (1986) e de Lopes (1998), uma vez que apresenta dados relevantes para a pesquisa: o pretérito imperfeito, o presente do indicativo e as formas nominais (infinitivo e gerúndio) favorecem o uso de "a gente", sendo o pretérito perfeito e os tempos que se caracterizam por apresentarem o maior número de marcas são condicionantes ao uso de "nós".

Para Fernandes e Görski (1986), a desinência flexional -mos tem assumido a função de morfema de pretérito, opondo-se ao morfema $\varnothing$, que passa a representar o tempo presente. Assim, pressupõe-se que o pronome "nós" esteja condicionado a verbos do tempo pretérito, enquanto a forma pronominal "a gente" se vincula a verbos no presente.

Os resultados obtidos a partir da análise do fator tempo nos permitiu constatar que a alternância pronominal nós/a gente perpassa todos os tempos. A distribuição/proporção dos tempos no uso das formas ("nós" e "a gente") na FPVCé bastante semelhante (Tabela 3). Todavia, nos dados de FPVC, a forma P4 - verbo flexionado por desinência - mos - é atestada apenas no presente e no pretérito perfeito. Também é apenas nestes casos que se atesta sujeito nulo sem antecedente "nós" ou "a gente" no discurso. Ressaltamos que o tempo presente do modo indicativo e tempo pretérito perfeito do indicativo possuem, segundo Villalva $(2003)^{15}$, os traços de

\footnotetext{
${ }^{14}$ Para as formas nominais (infinitivo e gerúndio) a frequência de “a gente” é superior a 90\%.

${ }^{15}$ De acordo com Villalva (2003), verifica-se que em seis paradigmas de flexão verbal (pretérito mais-que-perfeito e pretérito imperfeito do indicativo, pretérito imperfeito, presente e futuro do subjuntivo e infinitivo flexionado) as categorias de tempo-modo-aspecto (TMA) e de pessoa-número (PN) são realizadas por sufixos independentes, numa sequência que gera obrigatoriamente primeiro o sufixo TMA seguido do sufixo de PN. Entretanto, os tempos presente e pretérito perfeito do indicativo não dispõem de sufixos diferentes para TMA e PN, havendo uma amálgama de TMA e PN nos sufixos de flexão que compõem estes paradigmas verbais.
} 
tempo, modo, aspecto, pessoa e número amalgamados em um único morfema flexional do paradigma destes tempos, no modo indicativo. De acordo com essa proposta, o sufixo - mos, encontrado nos tempos presente e pretérito perfeito do indicativo, não possui os mesmos traços morfossintáticos do sufixo - mos que pode aparecer nos demais tempos e modos, o que pode sugerir que tanto a variação no uso das formas pronominais ("nós" e "a gente”) com $\varnothing$, "nós” com -mos e nulo com - mos, quanto ao próprio uso da desinência "mos" esteja relacionada a questões morfossintáticas.

Se assumirmos as hipóteses de Fernandes e Görski (1986) e Villalva (2003), podemos explicar a alta frequência (100\% dos casos) da desinência -mos nos tempos presente e pretérito perfeito) do modo indicativo, não pela variação da concordância, mas pelo fato de esta desinência não realizar apenas os traços concordantes de pessoa e número, já realizados no pronome, mas também os traços de tempo e modo.

\begin{tabular}{|c|c|c|c|c|c|c|c|c|c|}
\hline \multirow{3}{*}{ Tempo verbal } & \multicolumn{4}{|c|}{ Nós } & \multirow{3}{*}{ Total } & \multicolumn{2}{|c|}{ A gente } & \multirow{3}{*}{ Total } & Nulo \\
\hline & \multicolumn{2}{|c|}{ Explícito } & \multicolumn{2}{|c|}{ Implícito } & & Explícito & Implícito & & Implícito \\
\hline & P3 & $\underline{\mathrm{P} 4}$ & P3 & $\underline{\mathrm{P} 4}$ & & P3 & P3 & & $\underline{\mathrm{P} 4}$ \\
\hline Presente & 56 & $\underline{26}$ & 3 & $\underline{4}$ & 88 & 236 & 32 & 268 & $\underline{5}$ \\
\hline Pret. Perfeito & 25 & $\underline{3}$ & 6 & $\underline{2}$ & 36 & 8 & 2 & 10 & $\underline{13}$ \\
\hline Pret. Imperfeito & 39 & 0 & 6 & 0 & 45 & 57 & 11 & 68 & 0 \\
\hline Futuros & 2 & 0 & 0 & 0 & 2 & 1 & 0 & 1 & 0 \\
\hline Formas nominais* & 4 & 0 & 1 & 0 & 5 & 35 & 11 & 46 & 0 \\
\hline Condicional & 0 & 0 & 0 & 0 & 0 & 7 & 0 & 7 & 0 \\
\hline Total & 126 & 29 & 16 & 6 & 177 & 344 & 56 & 400 & 18 \\
\hline
\end{tabular}

Tabela 3: Tempo verbal na alternância pronominal nós/a gente, em números absolutos. Fonte: Elaboração própria com base nos resultados de Vieira (2014)

A tabela 3 também sugere que o pretérito perfeito e as formas nominais apresentam um favorecimento em relação a uma ou outra forma pronominal, sendo o primeiro favorecedor do uso de "nós" e o segundo de "a gente". Isso parece corroborar os resultados de Omena (1986), com falantes menos escolarizados, e de Lopes (1998), com falantes cultos.

Diante do exposto, reconhecemos o fator tempo verbal como relevante para as análises da alternância pronominal nós/a gente para o preenchimento lexical do sujeito de primeira pessoa plural e sujeito nulo, pois se trata de um grande influenciador, no caso de nossa amostra, um fator determinante, do uso de uma ou outra forma pelos falantes.

O tempo futuro não foi produtivo nos dados e a sua baixa frequência pode ser consequência da natureza "narrativa" das entrevistas, em que os informantes relatam situações já vividas por eles mesmos ou por terceiros. Dessa forma, a tendência é que o falante utilize mais os tempos do passado e do presente.

Da mesma maneira, nas formas nominais (infinitivo, gerúndio e particípio) ocorre apenas um sufixo da categoria de TMA (-r, -ndo e -do, respectivamente), sendo considerados paradigmas defectivos em PN. 


\subsubsection{SALIÊNCIA FÔNICA}

Rubio (2012) defende que o fator saliência fônica influencia na seleção do pronome de $1^{\text {a }}$ pessoa do plural, sendo que quanto maiores os níveis de saliência (exceto o grupo saliência esdrúxula) maior o emprego do pronome “nós”.

Para analisar o fator saliência fônica, Rubio (2012) propõe a seguinte divisão:

i) saliência esdrúxula - a forma de primeira pessoa do plural é proparoxítona e a oposição vogal/vogal-mos não é tônica nas duas formas. Ex. cantava/cantávamos, fazia/fazíamos, tivesse/tivéssemos;

ii) saliência máxima - ocorre mudança no radical e a oposição vogal/vogal-mos é tônica em uma ou duas formas. Ex.: é/somos, fez/fizemos, veio/viemos;

iii) saliência média - ocorre uma semivogal na forma de terceira pessoa do singular que não ocorre na forma de primeira pessoa do plural e a oposição vogal/vogal-mos é tônica nas duas formas. Ex.: comprou/compramos, foi/fomos, partiu/partimos, vai/vamos;

iv) saliência mínima - a oposição vogal/vogal-mos é tônica em uma ou nas duas formas, mas não há mudança no radical. Ex.: assiste/assistimos, canta/cantamos, dá/damos, está/estamos, fazer/fazermos, faz/fazemos, lê/lemos, será/seremos, trouxe/trouxemos, tem/temos. (RUBIO, 2012, p. 171-2)

Considerando Villalva (2003) e nossas constatações, expostas na seção anterior, optamos por considerar o fator tempo verbal relevante para o estudo da alternância pronominal nós/a gente, fazendo a intersecção com a saliência fônica. Os nossos resultados se apresentaram da seguinte forma:

\begin{tabular}{|c|c|c|c|c|}
\hline & Nós & Nulo & A gente & Total \\
\hline Esdrúxula & $\begin{array}{c}44 \\
\rightarrow 39,3 \% \\
(\downarrow 24,8 \%)\end{array}$ & 0 & $\begin{array}{c}68 \\
\rightarrow 60,7 \% \\
(\downarrow 17,0 \%)\end{array}$ & $\begin{array}{c}112 \\
(\downarrow 18,8 \%)\end{array}$ \\
\hline Máxima & $\begin{array}{c}15 \\
\rightarrow 62,5 \% \\
(\downarrow 8,5 \%)\end{array}$ & $\begin{array}{c}1 \\
\rightarrow 4,2 \% \\
(\downarrow 5,5 \%)\end{array}$ & $\begin{array}{c}8 \\
\rightarrow 33,3 \% \\
(\downarrow 2,0 \%)\end{array}$ & $\begin{array}{c}24 \\
(\downarrow 4,0 \%)\end{array}$ \\
\hline Média & $\begin{array}{c}46 \\
\rightarrow 39,3 \% \\
(\downarrow 26,0 \%)\end{array}$ & $\begin{array}{c}14 \\
\rightarrow 12,0 \% \\
(\downarrow 77,8 \%)\end{array}$ & $\begin{array}{c}57 \\
\rightarrow 48,7 \% \\
(\downarrow 14,3 \%)\end{array}$ & $\begin{array}{c}117 \\
(\downarrow 19,7 \%)\end{array}$ \\
\hline Mínima & $\begin{array}{c}72 \\
\rightarrow 21,1 \% \\
(\downarrow 40,7 \%)\end{array}$ & $\begin{array}{c}3 \\
\rightarrow 0,9 \% \\
(\downarrow 16,8 \%)\end{array}$ & $\begin{array}{c}267 \\
\rightarrow 78.0 \% \\
(\downarrow 66,7 \%)\end{array}$ & $\begin{array}{c}342 \\
(\downarrow 57,5 \%)\end{array}$ \\
\hline Total & $\begin{array}{c}177 \\
\rightarrow 29,8 \%\end{array}$ & $\begin{array}{c}18 \\
\rightarrow 3,0 \%\end{array}$ & $\begin{array}{c}400 \\
\rightarrow 67,2 \%\end{array}$ & $\begin{array}{c}595 \\
100 \%\end{array}$ \\
\hline
\end{tabular}

Tabela 4: Saliência fônica

Fonte: Vieira (2014, p. 54)

Na análise da Saliência Fônica verificamos que tanto "nós" (40,7\%) quanto "a gente" (66,7\%) são mais utilizados com verbos cuja saliência é considerada mínima; o sujeito nulo, porém, apresenta-se mais em verbos com saliência média 77,8\%.

Ao cruzarmos os fatores saliência fônica e tempo verbal, obtivemos os seguintes resultados: 


\begin{tabular}{|c|c|c|c|c|c|c|c|c|c|}
\hline \multicolumn{2}{|c|}{ Tempo } & \multirow{2}{*}{$\begin{array}{c}\text { Presente } \\
0\end{array}$} & \multirow{2}{*}{\begin{tabular}{|c|} 
Pret. Perfeito \\
0
\end{tabular}} & \multirow{2}{*}{$\begin{array}{c}\text { Pret. } \\
\text { imperfeito } \\
45\end{array}$} & \multirow{2}{*}{$\begin{array}{c}\text { Futuros } \\
0\end{array}$} & \multirow{2}{*}{$\begin{array}{c}\text { Cond. } \\
0\end{array}$} & \multirow{2}{*}{$\begin{array}{c}\text { Formas } \\
\text { nominais } \\
0\end{array}$} & \multicolumn{2}{|c|}{ Total } \\
\hline \multirow{4}{*}{ Nós } & ed & & & & & & & 45 & \multirow{4}{*}{177} \\
\hline & $\mathrm{mx}$ & 12 & 3 & 0 & 0 & 0 & 0 & 15 & \\
\hline & $\mathrm{md}$ & 13 & 33 & 0 & 0 & 0 & - & 46 & \\
\hline & $\mathrm{mn}$ & 64 & 0 & 0 & 2 & 0 & 5 & 71 & \\
\hline \multirow{4}{*}{ A gente } & ed & 0 & 0 & 67 & 0 & 1 & 0 & 68 & \multirow{4}{*}{400} \\
\hline & $m x$ & 7 & 0 & 0 & 0 & 1 & 0 & 8 & \\
\hline & $\mathrm{md}$ & 47 & 9 & 0 & & 1 & 0 & 57 & \\
\hline & $\mathrm{mn}$ & 214 & 1 & 1 & 1 & 4 & 46 & 267 & \\
\hline \multirow{4}{*}{ Nulo } & ed & - & - & - & - & - & - & - & \multirow{4}{*}{18} \\
\hline & $\mathrm{mx}$ & 1 & - & - & - & - & - & 1 & \\
\hline & $\mathrm{md}$ & 1 & 13 & - & - & - & - & 14 & \\
\hline & $\mathrm{mn}$ & 3 & - & - & - & - & - & 3 & \\
\hline \multicolumn{2}{|c|}{ Total } & 362 & 59 & 113 & 3 & 7 & 51 & & 95 \\
\hline
\end{tabular}

Tabela 5: Saliência fônica X tempo verbal

Fonte: Vieira (2014,p. 55)

É possível verificar na tabela 5 que a saliência esdrúxula atinge 100\% das formas do pretérito imperfeito, que, por sua vez, abrange tanto o uso de "nós" quanto o de "a gente". Os tempos presente e o pretérito perfeito, por apresentarem apenas um paradigma de morfemas (e não dois, como nos outros tempos), com os valores modo-temporal e número-pessoal amalgamados, possuem, naturalmente, maiores casos de saliência mínima ou média. Verifica-se, assim, que o fator saliência fônica está altamente associado ao fator tempo verbal, podendo ser este, e não aquele, o fator relevante para o funcionamento do paradigma flexional do verbo na FPVC.

\subsubsection{Controle do referente}

Muitos trabalhos sobre alternância pronominal apontam grau de determinação do referente como relevante para a pesquisa. Segundo Buescu (1961 apud PEREIRA, 2003), o pronome "a gente" se refere a um número não limitado, enquanto o pronome "nós" apresenta maior concretude, referindo-se a um número mais completo ou determinado de pessoas.

Lopes (1998), ao analisar o grau de determinação do referente em falantes cultos, fator chamado por ela de "eu-ampliado", revela a existência de diferenças importantes que favorecem o uso de "nós" ou de "a gente", relacionadas a um uso mais restrito ou mais genérico. O falante prefere usar "nós", quando o referente é [+perceptível] e [+determinado]; por outro lado, há favorecimento da forma "a gente" em situações cujo referente é mais indeterminado, com maior grau de impessoalidade.

Lemos Monteiro (1991) apresenta resultados que mostram uma diferenciação no emprego de "nós" e "a gente" referente ao uso mais restrito ou mais genérico. Segundo o autor, o falante prefere o pronome "nós" quando tem como referente ele mesmo e o 
interlocutor (eu+você), ou (eu+ele) “não-pessoa”, referente [+perceptível] e [+determinado]. Quando o falante amplia a referência, indeterminando-a, existe uma priorização pela forma "a gente". Lemos Monteiro (1991) afirma ainda que esse valor genérico, difuso e indeterminado das formas "nós" e "a gente", além de "você", se reflete na própria desinência verbal. Sendo assim, a impessoalidade verbal se coaduna com a noção de amplitude em que as formas pronominais são empregadas.

Omena (1986) verifica que a variante "nós" é privilegiada quando o sujeito abrange um grupo grande e determinado, enquanto a forma "a gente" refere-se mais a um grupo grande, porém indeterminado. A autora ressalta ainda que talvez o uso de "a gente" em substituição ao pronome "nós" esteja relacionado à necessidade de contrapor uma referência precisa a uma imprecisa, ratificando o que expõem Rollemberg et al. (1991) ao dizerem que "a gente" possui um grau generalizador de abrangência maior do que "nós", que sempre inclui o comprometimento do "eu".

Omena (1996) faz um levantamento sobre a influência do grau de determinação do referente na escolha dos morfemas de concordância verbal, afirmando que os casos de referentes mais específicos e definidos, nos quais o falante nitidamente se inclui, favorecem o uso da desinência de $1^{\text {a }}$ pessoa do plural, independentemente se a forma do sujeito pronominal é "nós" ou "a gente".

Para o fator controle de referente, obtivemos os seguintes resultados:

\begin{tabular}{|c|c|c|c|c|}
\hline & Nós & Nulo & A gente & Total \\
\hline Genérico e indefinido & $\begin{array}{c}22 \\
\rightarrow 13,7 \% \\
(\downarrow 12,5 \%)\end{array}$ & $\begin{array}{c}1 \\
\rightarrow 0,6 \% \\
(\downarrow 5,6 \%)\end{array}$ & $\begin{array}{c}138 \\
\rightarrow 85,7 \% \\
(\downarrow 34,5 \%)\end{array}$ & $\begin{array}{c}161 \\
(\downarrow 27,1 \%)\end{array}$ \\
\hline Genérico e definido & $\begin{array}{c}45 \\
\rightarrow 34,1 \% \\
(\downarrow 25,4 \%)\end{array}$ & 0 & $\begin{array}{c}87 \\
\rightarrow 65,9 \% \\
(\downarrow 21,7 \%)\end{array}$ & $\begin{array}{c}132 \\
(\downarrow 22,2 \%)\end{array}$ \\
\hline $\begin{array}{l}\text { Específico e definido } \\
\text { (homens) }\end{array}$ & $\begin{array}{c}23 \\
\rightarrow 27,7 \% \\
(\downarrow 13,0 \%)\end{array}$ & $\begin{array}{c}1 \\
\rightarrow 1,2 \% \\
(\downarrow 5,6 \%)\end{array}$ & $\begin{array}{c}59 \\
\rightarrow 71,1 \% \\
(\downarrow 14,7 \%)\end{array}$ & $\begin{array}{c}83 \\
(\downarrow 13,9 \%)\end{array}$ \\
\hline $\begin{array}{c}\text { Específico e definido } \\
\text { (mulheres) }\end{array}$ & $\begin{array}{c}5 \\
\rightarrow 17,9 \% \\
(\downarrow 2,8 \%)\end{array}$ & $\begin{array}{c}4 \\
\rightarrow 14,3 \% \\
(\downarrow 22,2 \%)\end{array}$ & $\begin{array}{c}19 \\
\rightarrow 67,9 \% \\
(\downarrow 4,9 \%)\end{array}$ & $\begin{array}{c}28 \\
(\downarrow 4,7 \%)\end{array}$ \\
\hline $\begin{array}{l}\text { Específico e definido } \\
\text { (misto) }\end{array}$ & $\begin{array}{c}82 \\
\rightarrow 42,9 \% \\
(\downarrow 46,3 \%)\end{array}$ & $\begin{array}{c}12 \\
\rightarrow 6,3 \% \\
(\downarrow 66,6 \%)\end{array}$ & $\begin{array}{c}97 \\
\rightarrow 50,8 \% \\
(\downarrow 24,3 \%)\end{array}$ & $\begin{array}{c}191 \\
(\downarrow 32,1 \%)\end{array}$ \\
\hline Total & $\begin{array}{c}177 \\
\rightarrow \mathbf{3 0 , 0} \%\end{array}$ & $\begin{array}{c}18 \\
\rightarrow 3,0 \%\end{array}$ & $\begin{array}{c}400 \\
\rightarrow 67,0 \%\end{array}$ & $\begin{array}{c}595 \\
100 \%\end{array}$ \\
\hline
\end{tabular}

O uso de "a gente", na função sujeito, se dá para todos os tipos de referentes (Tabela 6), todavia, sua maior freqüência se deu com referente genérico e indefinido (34,5\%). O uso de "nós", na função sujeito, também se dá em todos os contextos, porém, diferentemente do uso de "a gente", o pronome "nós" tem como referente mais frequente um referente específico e definido (misto) (46,3\%). Com relação ao pronome nulo, é válido ressaltar que, em quase sua totalidade (94,4\%, na soma dos definidos), o seu referente é específico e definido. O fato de o pronome "nós" ser mais utilizado em contextos de referente específico e definido e de o pronome "a gente" ser mais utilizado em contextos de referente genérico (definido e indefinido) corrobora, em certa medida, as 
hipóteses de Omena (1986). Todavia, a afirmação de que os casos de referentes mais específicos e definidos favorecem o uso da desinência de $1^{\text {a }}$ pessoa do plural -mos, independentemente da forma do sujeito pronominal, se "nós" ou "a gente", não pode ser sustentada para o nosso corpus uma vez que: a) todas as nossas construções com "a gente" apresentam morfema $\varnothing$, como exemplificado em (22) e (23), b) 34,6\% dos casos de "nós" genérico e indefinido concordam com P4, como exemplificado em (21), c) com o referente específico e definido, 78\% das realizações de "nós" concordam com P3, como exemplificado em (24) e d) os casos de sujeitos nulos sem forma pronominal antecedente são, na sua totalidade, apresentados junto a desinência - mos -, como exemplificado em (25) sendo quase a totalidade desse "sujeito desinencial" específico e definido, 99,4\%, conforme podemos constatar na tabela 6 .

(21) "O que gera a violencia é falta de emprego, falta de policiamento bom na cidade, falta de várias coisas que nós precisamos em Vitória da Conquista." (ETM, 1f) - referente genérico e indeterminado

(22) "Ele coleta o lixo e joga num vasilhão cá embaixo, é de carroça, aí a gente já levanta cedo, já tem os dia, a gente levanta a hora que levanta, na hora que (agente) vai saí pro trabalho, bota o lixo pra fora na porta, aí ele ele, o carroceiro recolhe e bota no vasilhão." (ETM, 1f) - referente genérico e determinado

(23) "A gente num pode também chegar e falar tambémnão né? errar e a gente falar não, eu num tô mais do seu lado e virar as costa" (MCF, 2m) - referente específico e definido exclusivo homens

(24) "Então, nós trabalhava, fazia qualquer coisinha assim pros outro pra ganhar uns trocadinhos." (ETM, 1f) - referente específico e definido exclusivo mulheres

(25) "Moremos assim na roça que meu pai era era era faz:.... vaqueiro." (MdS, 3f) - - referente específico e definido misto

Assim, a hipótese de Omena (1986) deve ser reformulada e aplica-se apenas aos casos de sujeito nulo de primeira menção, ou seja, sem referente antecedido no discurso.

Em síntese, observamos que, no corpus FPVC, a forma "nós" não é exclusiva de referentes específicos, apesar de se apresentar em maior uso com o referente específico e determinado, [+perceptível] e [+determinado], não havendo relação entre a especificidade do referente e a concordância com P4, uma vez que há casos de referentes mais específicos concordando com P3, e a forma "a gente" não é exclusiva de referentes indefinidos, apesar de preferir contextos de referente indeterminado (genérico), com maior grau de impessoalidade. Observamos ainda que os casos de sujeito nulo (de primeira menção, ou seja, sem antecedente expresso) possuem referentes específicos e determinados em quase a totalidade dos dados.

\section{O PAPEL DA FLEXÃO E DA CONCORDÂNCIA NO USO DAS FORMAS PRONOMINAIS NA FUNÇÃO SUJEITO}

Os estudos de mudança no quadro teórico gerativista buscam identificar as relações de causa e efeito da mudança, o que torna frequente o embate com a questão sobre a ordem das relações nas construções gramaticais. Nesse sentido, questionamos: A gramaticalização das novas formas pronominais "você" e "a gente" é a causa para as mudanças no paradigma flexional do PB? Para responder a esta questão pode-se levantar uma hipótese, comumente levantada, mas que refutamos, de que formas de terceira pessoa com sentidos de segunda pessoa e de primeira do plural causaram uma desestabilização no sistema de concordância e, consequentemente, uma redução do paradigma flexional do verbo no PB. Outra resposta possível para a questão seria a hipótese de não haver relação de causa e de efeito entre os elementos trazidos na questão, sendo a gramaticalização das formas "você" e "a gente", a mudança nos paradigmas da flexão verbal e outras alterações percebidas no vernáculo brasileiro, todos efeitos de mudança profunda (e não gatilhos).

Uma vez que "a gente vamos" é forma atestada na Europa desde o século XVIII, e que não há notícias de que "*ocê vais" tenha sido atestado em PE ou em PB, a relação entre a generalização do uso da flexão verbal Ø e a entrada das novas formas "você" e "a gente" 
no paradigma pronominal do PB não nos parece assim tão óbvia. Somemos isso ao importante fato de que o uso de terceira pessoa como tratamento de segunda pessoa é bastante comum em Portugal ${ }^{16}$, não tendo este fato afetado o paradigma flexional do PE.

Várias hipóteses têm sido lançadas numa tentativa de justificar as alterações na gramática do PB, todas desenvolvidas em torno da primeira resposta à questão aqui apresentada. Tarallo (1993) e Duarte (1993), por exemplo, relacionam a baixa produtividade de sujeito nulo à inserção de novas formas pronominais ao paradigma do PB. Segundo os autores, a preferência pela realização do sujeito pronominal no PB e a redução do paradigma flexional seriam, ambos, resultados da inovação no paradigma de pronomes.

Paiva e Duarte (2006, p.141) comentam essa tendência ao preenchimento do sujeito, reforçando essa ideia:

Uma hipótese possível para o curso dessa mudança estaria no enfraquecimento do sistema de flexões verbais decorrente da substituição de pronomes que se combinam com formas verbais de desinência exclusiva ("tu" e "nós") por pronomes que se combinam com formas verbais de terceira pessoa do singular ("você" e "a gente"). Tais substituições (ou a neutralização entre "tu" e "você") reduziu o número de oposições de cinco para apenas três formas verbais distintas, que podem passar a duas no caso da ausência de marca de concordância na terceira pessoa do plural. (PAIVA; DUARTE, 2006).

O preenchimento do sujeito pode ser um dos efeitos da mudança, o que, a nosso ver, não implica necessariamente que esteja encadeado à inserção de novos pronomes na língua. Essa relação talvez não seja sempre necessária. Talvez o gatilho não seja a concordância das formas "a gente" e "você" com Ø, e isso requer uma investigação maior.

Galves (1993) pressupôs que a mudança profunda que caracteriza a mudança gramatical no PB esteja localizada no enfraquecimento da concordância, uma vez que essa mudança na caracterização do morfema de concordância (Agr) presente na flexão remete a uma reestruturação da oração subjacente a todas as mudanças superficiais. A autora assume que essa "retenção pronominal" representa uma mudança qualitativa e não só uma variação quantitativa produzida numa mesma gramática. A autora atesta que a concordância verbal no PB é "fraca”, o que corroboraria a sua hipótese:

É fraca a concordância que não contém pessoa, ou que contém pessoa como um traço puramente sintático. É o que acontece no $\mathrm{PB}$ onde não se encontra na flexão verbal a oposição $1^{\mathrm{a}}$, $2^{\mathrm{a}}$ e $3^{\mathrm{a}}$ pessoas, mas somente uma oposição binária, pessoa (1ª)/não pessoa (3ª), articulada a uma oposição singular/plural. (GALVES, 1993, p. 395)

Trata-se, portanto, de uma concordância morfológica fraca, por falta da segunda pessoa, e de uma concordância semântica também fraca, já que o morfema característico de $3^{\text {a }}$ pessoa do singular $(\varnothing)$ é interpretado como indeterminado. Vale ressaltar que Benveniste (2005) atribui a noção de pessoa do discurso somente à primeira e segunda pessoas, que são aquelas que participam diretamente do processo de enunciação. Sobre a terceira pessoa, o autor a caracteriza como a "não-pessoa", já que esta, enquanto enunciado de discurso, remete a uma situação objetiva, podendo comportar qualquer sujeito ou não representar nenhum; é uma forma não pessoal da flexão verbal.

Galves (1993) se apropria de noções mais abstratas para ratificar a sua hipótese de enfraquecimento da concordância, que levam à análise da oração em que a flexão de pessoa desempenha papel crucial - o papel de núcleo. Diferentemente do que tem sido apresentado pela literatura, Galves propõe que "um morfema de concordância fraco não é gerado em um núcleo independente, mas antes como um afixo a T, desde o início da derivação" (GALVES, 1993, p. 396), conforme modelo abaixo:

${ }^{16}$ Ana vai ao cinema conosco? Ana é $2^{\text {a }}$ pessoa e a sentença pode ser parafraseada com: Tu vais ao cinema conosco? 


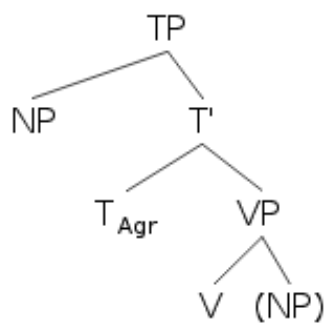

Assim, Galves (1993) conclui que o enfraquecimento da flexão provoca uma reorganização da oração: o sujeito se encontra numa posição mais baixa do que numa língua de concordância forte, em que este estaria na posição de especificador de Agr. Quando Agr se enfraquece, o morfema Agr e o núcleo Agr se dissociam. Essa interpretação justifica a preferência por objetos nulos e o enfraquecimento dos clíticos, bem como a legitimação do pronome tônico em posição de objeto e o desaparecimento do se apassivador. $\mathrm{O}$ enfraquecimento da concordância também pode ser relacionado à modificação das formas pronominais de tratamento, em que se perdeu a oposição tu ( $2^{\mathrm{a}}$ pessoa)/você ( $3^{\mathrm{a}}$ pessoa). Da mesma maneira, observamos que a alternância nós/a gente pode estar relacionada ao enfraquecimento da concordância verbal, principalmente devido ao aumento do uso da forma pronominal tradicional concordando com a terceira pessoa (Nós+ Ø).

Mais recentemente, embasada nos pressupostos minimalistas, Béjar (2003) apresenta uma teoria de traços para a concordância, que poderia explicar a ideia inicial de Galves (1993) sobre o enfraquecimento da concordância. Para tanto, a autora assume que os pronomes obedecem a uma geometria interna responsável por sua sistematização, em que $\varphi$ codifica as propriedades nominais de concordância (pessoa, número e gênero), e adiciona um novo traço $\pi$, como uma camada representativa, a essa geometria, que se apresentaria como um nó intermediário entre a raiz do elemento referencial e o nó [PARTICIPANT]. $\pi$ é um traço semântico para a categoria pessoa, reponsável sozinho por diferenciar as $1^{\text {a }}, 2^{\mathrm{a}}$ e $3^{\mathrm{a}}$ pessoas. A proposta de Béjar (2008) é motivada por algumas restrições que ocorrem em casos de concordância, quando há falta de equivalência entre os traços do elemento controlador (alvo) e os do elemento controlado (sonda). Por essa proposta, os tradicionais traços- $\varphi$ pronominais de pessoa, número e gênero são assumidos como não primitivos, sendo representados por diferentes tipos de feixes de traços. No que se refere ao traço de pessoa, $o$ inventário adotado é $\{[\pi]$, [participant], [speaker] e para o número $\{[\omega]$ [plural] $\}$. Esses traços são privativos, o que significa que sua ausência é interpretada como um valor negativo.

A análise de Béjar (2008) dá conta, a partir da noção de acarretamento, dos pareamentos possíveis no processo de concordância, alvo-sonda (goal-probe), levando em consideração que no processo de concordância deve haver pareamento de ao menos um dos traços, necessitando que os traços contidos na sonda sejam iguais ou subconjuntos dos traços contidos no alvo:

\begin{tabular}{|c|c|c|c|c|}
\hline Padrão & Alvo & Sonda & AGREE pessoa & AGREE número \\
\hline $\begin{array}{l}\text { A gente - } \\
\mathrm{T}(\mathrm{u} \varphi: 3 ; \mathrm{SG})\end{array}$ & $\begin{array}{c}{[\pi \text { participant speaker }]} \\
{[\omega \text { plural }]}\end{array}$ & {$[\mathrm{u} \pi][\mathrm{u} \omega]$} & $\begin{array}{c}\qquad \mathscr{G}_{\mathbf{I}} \\
\text { agree succeeds }\end{array}$ & $\begin{array}{c}\qquad \mathscr{P}_{\mathrm{I}} \\
\text { agree succeeds }\end{array}$ \\
\hline $\begin{array}{l}\text { A gente - } \\
\mathrm{T}(\mathrm{u} \varphi: 1 ; \mathrm{PL})\end{array}$ & $\begin{array}{c}{[\pi \text { participant speaker }]} \\
{[\omega \text { plural }]}\end{array}$ & 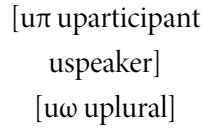 & $\begin{array}{l}\mathrm{P} \mathscr{G}_{\mathrm{I}} \text { and } \mathrm{P} \beth_{\mathrm{J}} \\
\text { agree succeeds }\end{array}$ & $\begin{array}{l}\mathrm{P} \mathscr{G}_{\mathrm{I}} \text { and } \mathrm{P} \beth_{\mathrm{I}} \\
\text { agree succeeds }\end{array}$ \\
\hline
\end{tabular}

Tabela 8: Processos de concordância com as novas formas pronominalizadas do português, a partir da proposta de Béjar (2008).

Fonte: Vieira (2014, p. 25)

Os traços de gênero, por sua vez, têm seus valores marcados na terceira pessoa e são a marcados nas outras pessoas. Dessa forma, $o$ pronome "a gente", assim como os demais pronomes de primeira pessoa e os de segunda pessoa, apesar de aparentar ausência de gênero, pode estabelecer concordância em estruturas predicativas, advertindo que em uma mesma forma pronominal os traços $\varphi$ podem se comportar de forma diferente. 
Assim, a variação no uso de "nós" e de "a gente" concordando com Ø (nós/a gente foi) e "nós" e "a gente" concordando com -mos (nós/a gente fomos) deve estar relacionada a uma mudança profunda que afeta o paradigma flexional do verbo; também evidenciada pela existência de concordância de P6 com $\varnothing$ (ex.: Eles canta), mantendo uma oposição singular entre -o e $\emptyset$, tendo $\emptyset$ para qualquer sujeito diferente de EU, independente das características de Pessoa e Número desse sujeito.

\section{CONSIDERAÇÕES FINAIS}

Para argumentar a favor da hipótese aqui defendida, discorremos sobre trabalhos importantes que discutem as características do $\mathrm{PB}$, principalmente no que diz respeito aos pronomes e aos fenômenos associados a esta categoria gramatical, ancorando-nos nos pressupostos gerativistas que ditam a modelagem dos dados e as hipóteses de mudança.

Partindo desse quadro teórico, comprovar a natureza da variação nós/a gente no paradigma pronominal está longe de ser uma tarefa simples. Questiona-se aqui a natureza dessa variação, por se julgar que não há, nos trabalhos anteriores, elementos suficientes para afirmar que "nós" e "a gente" são formas em competição, mais especificamente, a gramaticalização de "a gente" como pronome de $1^{\text {a }}$ pessoa do plural não parece desencadear o desaparecimento da forma "nós" no sistema pronominal do PB, observando-se apenas uma especificação das formas no uso.

A reanálise de trabalhos já desenvolvidos acerca do fenômeno nós/a gente e os resultados dos dados extraídos do corpus FPVC revelam a existência de ambientes linguísticos favoráveis ao uso de uma ou outra forma, demonstrando um convívio entre elas. Sua variação no uso parece refletir um sistema cuja principal característica é definir os traços do referente e, para argumentar a favor dessa hipótese, consideramos um aspecto importante do PB que nos serviu de base para a reflexão que desenvolvemos aqui, a respeito da gramática da língua, que permite um sistema pronominal com duas formas para P4: a não obrigatoriedade da concordância de número. Os falantes não costumam marcar de maneira redundante os traços de número e isso poderia justificar o grande aumento do uso de "nós" + morfema $\emptyset$, no PB e a especificação do morfema "-mos" para os casos de sujeitos nulos de primeira menção.

\section{REFERÊNCIAS}

BÉJAR, S. Conditions of phi-Agree. In: HARBOUR, D.; ADGER, E; BÉJAR, S. Phi Theory. Phi features across modules and interfaces. New York: Oxford University Press, 2008. p.130-154.

Phi-syntax: A theory of agreement. 2003. 107f. Tese (Doutorado). Universidade de Toronto, Toronto, 2003.

BORTONI-RICARDO, S.M. The urbanization of rural dialect speakers - a sociolinguistic study in Brazil. University Press: Cambridge, 1985.

CÂMARA JUNIOR, J. M.. Estrutura da língua portuguesa. 43. ed. Petrópolis, RJ: Vozes, 2011.

DUARTE, M. E. L. Do pronome nulo ao pronome pleno: a trajetória do sujeito no português do Brasil. In: ROBERTS, I.; KATO, M. A. (Org.). Português brasileiro: uma viagem diacrônica. Campinas: Editora da Unicamp, 1993. p. 107-128.

FERNANDES, E.; GORSKI, E. A concordância verbal com os sujeitos nós e a gente: um mecanismo do discurso em mudança. Actas do Simpósio sobre a Diversidade Linguística no Brasil. Salvador: Instituto de Letras da UFBA, 1986, p. 175-183.

GALVES, C. O enfraquecimento da concordância no português brasileiro. In: ROBERTS, I.; KATO, M. A. (Org.). Português Brasileiro: uma viagem diacrônica. Campinas: Editora da Unicamp, 1993. p. 387-408. 
KROCH, A. Syntactic change. In: BALTIN, M.; COLLINS, C. (Ed.). The handbook of contemporary syntactic theory. Oxforfd: Blackwell, 2001. p. 699-729..

Morphosyntactic variation. In: BEALS, K. et al. (Ed.). Papers from the 30th Regional Meeting of the Chicago Linguistics Society: Parasession on Variation and Linguistic Theory. Chicago: Chicago Linguistic Society, 1994. p. 1-23.

. Reflexes of grammar in patterns of language change. Language Variations and Change, v.1, p. 199-244, 1989a.

Function and Grammar in the History of English: Periphrastic 'do'. In: FASOLD, R.; SCHIFFRIN, D.( Ed.). Language Change and Variation. Amsterdam: Benjamins, 1989b, p. 133-172.

LEMOS MONTEIRO, J. Os pronomes pessoais no português do Brasil. - Tese de Doutoramento, Faculdade de Letras, Universidade Federal do Rio de Janeiro, Rio de Janeiro, 1991.

. Pronomes pessoais: subsídios para uma Gramática do português do Brasil. Fortaleza: Edições UFC, 1994.

LOPES, C. R. dos S. A inserção de "a gente" no quadro pronominal do português. Madrid: Iberoamericana, 2003.

. A inserção de a gente no quadro pronominal do português: percurso histórico. Rio de Janeiro, 1999. 167f.Tese (Doutorado em Linguística) - Faculdade de Letras, Universidade Federal do Rio de Janeiro, Rio de Janeiro, 1999.

. Nós e a gente no português falado culto do Brasil. DELTA, São Paulo, v. 14, n. 2. p. 405-422, 1998.

. Nós e a gente no português falado culto do Brasil. Rio de Janeiro, 1993. 189 f. Dissertação (Mestrado em Estudos Linguísticos) - Faculdade de Letras, Universidade Federal do Rio de Janeiro, Rio de Janeiro, 1993.

. Nós por a gente: uma contribuição da pesquisa sociolinguística ao ensino. In: CARDOSO, S. A. M. (Org.). Diversidade linguística e ensino. Salvador: EDUFBA, 1996. p. 115-123.

. O quadro dos pronomes pessoais. In: VIEIRA, S. R.; BRANDÃO, S. F. (Org.). Morfossintaxe e ensino de português: reflexões e propostas. Rio de janeiro: Faculdade de Letras, 2004. p. 151-178.

NARO, A. J.; GÖRSKI, E.; FERNANDES, E. Change without change. Language Variation and Change, v. 11, n. 2, p. $197-211,1999$.

OMENA, N. P. de. A referência variável da primeira pessoa do discurso no plural. In: NARO, A. et al. Relatório final de pesquisa: projeto subsídios do projeto censo à educação, Rio de Janeiro, UFRJ, v.2, p. 286-319, 1986.

As influências sociais na variação entre nós e a gente na função de sujeito. In: OLIVEIRA e SILVA, G. M.; SCHERRE, M.M.P. Padrões sociolinguísticos. Rio de Janeiro: Tempo Brasileiro, 1996. p. 309-323.

PAIVA, M. da C. A. de; DUARTE, M. E. L. Quarenta anos depois: a herança de um programa na sociolinguística brasileira. In: WEINREICH, U.; LABOV, W.; HERZOG, M. I. Fundamentos empíricos para uma teoria da sociolinguística. Trad. Marcos Bagno. São Paulo: Parábola, 2006. p.131-151.

PEREIRA, S.M.B. Gramática Comparada de a gente: variação no Português Europeu. Lisboa, 2003. 100f. Dissertação (Mestrado em Gramática Comparada) - Universidade de Lisboa, Lisboa, 2003.

RODRIGUES, A.C.S. A concordância verbal no português popular em São Paulo. São Paulo, 1987. 189 f. Tese (Doutorado em Língua Portuguesa) - Faculdade de Filosofia, Letras e Ciências Humanas, Universidade de São Paulo, São Paulo, 1987. 
ROLLEMBERG, V. et al. . Os pronomes pessoais e a indeterminação do sujeito na norma culta de Salvador. Estudos Linguísticos e Literários, Salvador,v.11, p. 53-74, 1991.

RUBIO, C.F. Padrões de concordância verbal e de alternância pronominal no português brasileiro e europeu: estudo sociolinguístico comparativo. São José do Rio Preto, 2012. 393f. Tese (Doutorado em Estudos Linguísticos) - Universidade Estadual Paulista, São José do Rio Preto, 2012.

TARALLO, F. Diagnosticando uma gramática brasileira: o português d'aquém e d'além-mar ao final do século XIX. In: ROBERTS, Ian ; KATP, M. A.(Org.). Português Brasileiro: uma viagem diacrônica. Campinas: Ed. da UNICAMP, 1993. p. 69-106.

VIANNA, J.B.S. Semelhanças e diferenças na implementação de a gente em variedades do português. Rio de Janeiro, 2011. 235f. Tese (Doutorado em Letras Vernáculas) - Faculdade de Letras, Universidade Federal do Rio de Janeiro, Rio de Janeiro, 2011.

VIANNA, J. B. de S.; LOPES, C. R. dos S. Nós e a gente na sincronia: correlação entre os traços formais e os semântico-discursivos. In: ENCONTRO DO CELSUL, 5., 2003, Curitiba. Anais... Curitiba: UFPR, 2003. p. 671-676.

VIEIRA, A. S. de O. Nós e a gente: um estudo sobre a sintaxe do Português Brasileiro. Vitória da Conquista-BA, 2014. 71f. Dissertação (Mestrado em Linguística) - Programa de Pós-Graduação em Linguística da Universidade Estadual do Sudoeste da Bahia, Vitória da Conquista, 2014.

VILLALVA, A. Estrutura morfológica básica. In: MATEUS, M. H. M et al. (Org.). Gramática da língua portuguesa. Lisboa: Ed. Caminho, 2003.p. 917-986. 